\title{
Structure and immunohistochemistry of the human lenticulostriate arteries
}

\author{
S. Marinković ${ }^{1}$, V. Todorović ${ }^{2}$, N. Drndarević ${ }^{3}$, L. Puškaš ${ }^{4}$, D. Lazić5 ${ }^{5}$ V. Bojićc ${ }^{6}$ I. Milić ${ }^{7}$ \\ ${ }^{1}$ Department of Neuroanatomy and Gross Anatomy, Institute of Anatomy, Faculty of Medicine, University of Belgrade, \\ Belgrade, Serbia \\ 2Department of Histology and Embryology, School of Dentistry Pančevo, University of Business Academy, \\ Novi Sad, Serbia \\ ${ }^{3}$ Department of Research, Faculty of Dentistry Pančevo, University of Business Academy, Novi Sad, and BeoLab, \\ Belgrade, Serbia \\ ${ }^{4}$ Department of Anatomy, Institute of Anatomy, Faculty of Medicine, University of Belgrade, Belgrade, Serbia \\ ${ }^{5}$ Department of Psychiatry, Psychiatric Clinic Laza Lazarević, Faculty of Medicine, University of Belgrade, \\ Belgrade, Serbia \\ ${ }^{6}$ Department Paediatrics, Pediatric Clinic, Faculty of Medicine, University of Belgrade, Belgrade, Serbia \\ ${ }^{7}$ Department of Neurosurgery, Clinic of Neurosurgery, Faculty of Medicine, University of Belgrade, Belgrade, Serbia
}

[Received 6 February 2013; Accepted 11 March 2013]

Background: Data about the structure and immunohistochemistry of the lenticulostriate arteries (LSAs), although very important for medical research and clinical practice, have been rarely reported in literature.

Materials and methods: Fourty serially sectioned LSAs were stained with hematoxilin and eosin, and prepared for immunohistochemistry.

Results: Our examination revealed a typical endothelial lining and a narrow subendothelial space with subintimal smooth muscle cells occasionally. The internal elastic lamina was fragmented or absent in the smallest LSAs branches. The media coat, with a mean diameter of $148.5 \mu \mathrm{m}$, contained typical smooth muscle cells which formed 14.2 layers on average and showed a positive immune reactions for alfa-actin, desmine, laminin and collagen IV. The thin adventitial coat contained fibroblasts, collagen fibers, and nerve bundles, with the strongest immunopositivity to thyrosin hydroxilase. The immune reactions against CD31 and CD34 proteins, endothelial nitric oxide synthase, 5100 protein, neurofilament protein and synaptophysin, seem to be performed in the LSAs wall for the first time. Similarly, the thickness of the LSAs wall and its coats have never been reported, nor the number of the smooth muscle cell layers.

Conclusions: Our results related to the structure and immunohistochemistry of the LSAs could be important in cerebrovascular pathology, neurology and neurosurgery. (Folia Morphol 2013; 72, 3: 210-216)

Key words: arterial wall, cerebrovascular spasm, immunohistochemistry, histology, lenticulostriate artery, perforating artery

\section{INTRODUCTION}

The lenticulostriate arteries (LSAs) represent the perforating branches of the proximal segment of the middle cerebral artery (MCA). There is a large body of the literature concerning the LSAs micro- anatomy, including their capsular and ganglionic regions of supply $[13,22,29]$. However, structure and immunohistochemistry of the LSAs or other perforating vessels of humans, as well as of some animals, were usually examined superficially, only 
Table 1. Details of the primary antibodies used in the immunohistochemical study

\begin{tabular}{|c|c|c|}
\hline Primary antisera (Species, Clone) & Manufacture/Lot number & Antibody dilution/Antigen retrieval \\
\hline CD31 (mouse, JC/70A)* & DAKO A/S, Denmark, M0823 & 1:20/ microwave oven, citrate buffer $\mathrm{pH} 6,21 \mathrm{~min}$ \\
\hline CD34 (mouse, BI-3C5)* & DAKO A/S, Denmark M 7168 & 1:25/ microwave oven, citrate buffer $\mathrm{pH}$ 6, 21 min \\
\hline$\alpha$-SMA (mouse, $1 \mathrm{~A} 4)^{*}$ & DAKO A/S, DenmarkM 0851 & $1: 25 /$ microwave oven, citrate buffer $\mathrm{pH} 6,21$ min \\
\hline Desmine (mouse, DE-R-11)* & DAKO A/S, Denmark, M0724 & 1:10/ microwave oven, citrate buffer $\mathrm{pH} 6,21 \mathrm{~min}$ \\
\hline Laminin (mouse, PHM12) & Novocastra, UK, NCL-LMININ & 1:20/ tripsine digestion, $10 \mathrm{~min}$ \\
\hline Collagen IV (mouse, PHM12)* & Novocastra, UK, NCL-COLL-IV & 1:20/ microwave oven, citrate buffer $\mathrm{pH} 6,2$ min \\
\hline S 100 (rabbit)** & DAKO A/S, Denmark Z 0311 & 1:300/ microwave oven, citrate buffer $\mathrm{pH}$ 6, 21 min \\
\hline Neurofilament protein (mouse, F11)* & DAKO A/S, Denmark, M0762 & 1:50/ microwave oven, citrate buffer $\mathrm{pH}$ 6, 21 min \\
\hline Synaptophysin (mouse, SY38)* & DAKO A/S, Denmark, M0776 & 1:10/ microwave oven, citrate buffer $\mathrm{pH} 6,21 \mathrm{~min}$ \\
\hline Tyrosine hydroxilase (mouse, 1B5) & Novocastra, UK, NCL-TH & 1:20/ pressure cooker, citrate buffer $\mathrm{pH} 6,2 \mathrm{~min}$ \\
\hline $\begin{array}{l}\text { Acetylcholinesterase } \\
\text { (mouse, AFMA183753)* }^{*}\end{array}$ & $\begin{array}{l}\text { Thermo Fisher Scientific, } \\
\text { Fremont, CA, MA1-83753 }\end{array}$ & 1:50/ microwave oven, citrate buffer $\mathrm{pH} 6,21 \mathrm{~min}$ \\
\hline Serotonin $(5-\mathrm{HT})^{* *}$ & Novocastra, UK, NCL-SEROTp & 1:100/ pressure cooker, citrate buffer pH 6, 21 min \\
\hline eNOS (mouse, NOS-125)* & Novocastra, UK, NCL-NOS-1 & $1: 25 /$ pressure cooker, citrate buffer $\mathrm{pH} 6,2$ min \\
\hline c-KIT/CD117 (rabbit) ${ }^{* *}$ & DAKO A/S, Denmark, A 4502 & 1:400/ microwave oven, citrate buffer $\mathrm{pH}$ 6, 21 min \\
\hline
\end{tabular}

*monoclonal antibodies; **polyclonal antibodies; see abbreviations in the text

as a necessary background of certain investigations, especially those regarding their vascular innervation or some cerebrovascular diseases and disorders $[1,5,6,9,14,18,28]$. Thus, to our knowledge, there is not any article in the last few decades which is specifically devoted to the LSAs structure or general immunohistochemistry.

Accordingly, our aim in this study was, first, to examine the histological appearance of the LSAs wall, including the corresponding measurements. The main goal was to explore the immunohistochemical features of the existing cellular components and certain constituents of the extracellular matrix in the tunica intima, media and adventitia of the LSAs.

\section{MATERIALS AND METHODS}

The LSAs were obtained from 20 hemispheres of 10 persons during routine autopsy, after providing approval from the authorities of the Institute of Pathology and the Ethical Committee of the University Clinical Center. Six males and 4 females, aged $17-66$ years (mean 50.9 ), underwent autopsy 5-24 h after death (mean 18.1). None of the patients had any neurological disease, except 3 persons with the histological signs of the atherosclerosis.

Two segments of the LSAs on each side were taken, so that a total of 40 specimens were collected. Each LSAs segment was immersed in isotonic saline solution, fixed in $4 \%$ neutral buffered formaldehyde, dehydrated, embedded in paraffin and sectioned se- rially in $5 \mu \mathrm{m}$-thick slices. Every tenth slice was stained with hematoxylin and eosin (HE).

The remaining slices of each set underwent the immunostaining using the selected primary antisera (Table 1) according to the usual procedure [2]. All slices were treated for antigen retrieval prior to staining. The slices were stained for certain antigens by streptavidin-biotin peroxidase complex method (Universal LSAB+ Kit HPR; DAKO ${ }^{\circledR}$ Cytomation K0679, Glostrup, Denmark) using as chromogens 3-amino-9-ethylcarbazole (AEC, No. K3469, DAKO ${ }^{\circledR}$ ) or 3,3'diaminobenzidine $\left(D A B+\right.$ chromogen, LSAB + System-HRP, DAKO $\left.{ }^{\circledR}\right)$. The sections were counterstained with Mayer's hematoxylin. The intensity of staining was evaluated semiquantitatively by 2 independent investigators, who classified the intensity as strongly $(+++)$, moderately $(++)$ or weakly positive $(+)$, or negative $(-)$. Positive and negative tissues were included as controls in order to determine the specificity of immunostaining. Finally, we also applied c-KIT and toluidine blue staining for identification of the mast cells.

\section{RESULTS}

The LSAs are small vessels whose wall thickness averaged $0.36 \mathrm{~mm}$ (Table 2 ). These perforating arteries often give rise to one or more side branches (Fig. 1) which can further ramify within the Sylvian cistern. The smallest twigs within the subarachnoid space contain only 1 smooth muscle layer in the media coat. The wall of the 
Table 2. Measurements of the lenticulostriate arteries

\begin{tabular}{cccc}
\hline \multicolumn{4}{c}{ Diameters: range (mean) } \\
\hline Wall $[\mathrm{mm}]$ & Internal elastic lamina $[\mu \mathrm{m}]$ & Media coat $[\mu \mathrm{m}]$ & Adventitial coat $[\mu \mathrm{m}]$ \\
\hline $0.22-0.91(0.36)$ & $4.3-14.6(8.1)$ & $102-218(148.5)$ & $66-175(109.3)$ \\
\hline
\end{tabular}

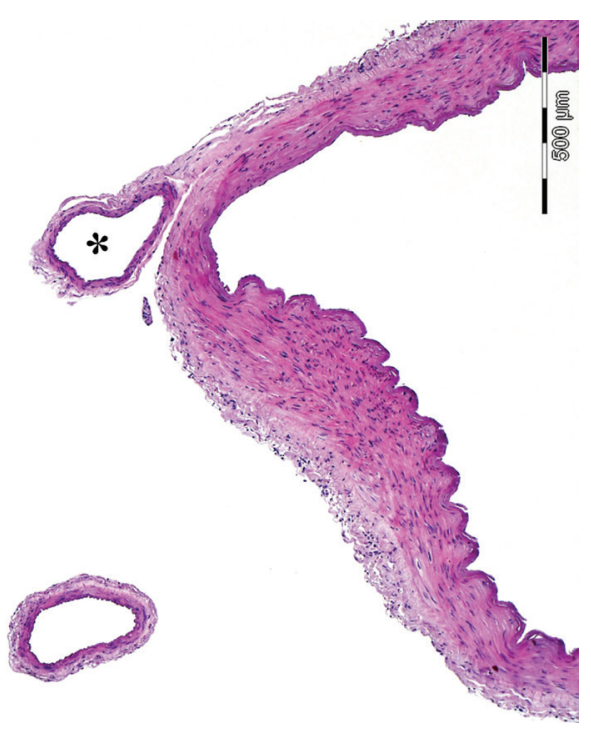

Figure 1. Transverse section of a lenticulostriate artery with origin of a side branch $\left({ }^{*}\right)$; HE staining.

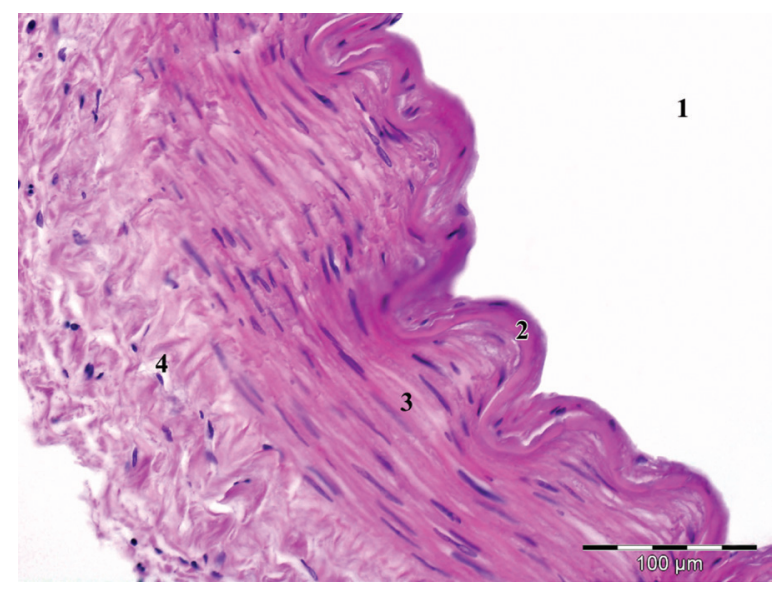

Figure 2. Transverse section of a lenticulostriate artery at higher magnification; 1 - lumen; 2 - internal elastic lamina extending along the border between the endothelial lining and tunica media (3); 4 - tunica adventitia; HE.

LSAs and their branches consists of 3 typical coaxial coats: tunica intima, media and adventitia (Fig. 2).

\section{Tunica intima}

The innermost coat comprises one continuous layer of the flattened endothelial cells with the elongated nuclei (Fig. 2). The immunohistochemical examination showed a strong or moderate immune reaction against CD31 and
Table 3. Intensity of the immune reaction

\begin{tabular}{lc}
\hline Primary antiserum & Intensity \\
\hline CD31 & $+++/++$ \\
CD34 & +++ \\
$\alpha$-SMA & +++ \\
DES & +++ \\
LM & +++ \\
Coll IV & +++ \\
S 100 & +++ \\
NF protein & +++ \\
SY & +++ \\
TH & +++ \\
AChE & $++/+$ \\
5-HT & - \\
eNOS & +++++ \\
C-KIT/CD117 & - \\
\hline
\end{tabular}

See abbreviations in the text

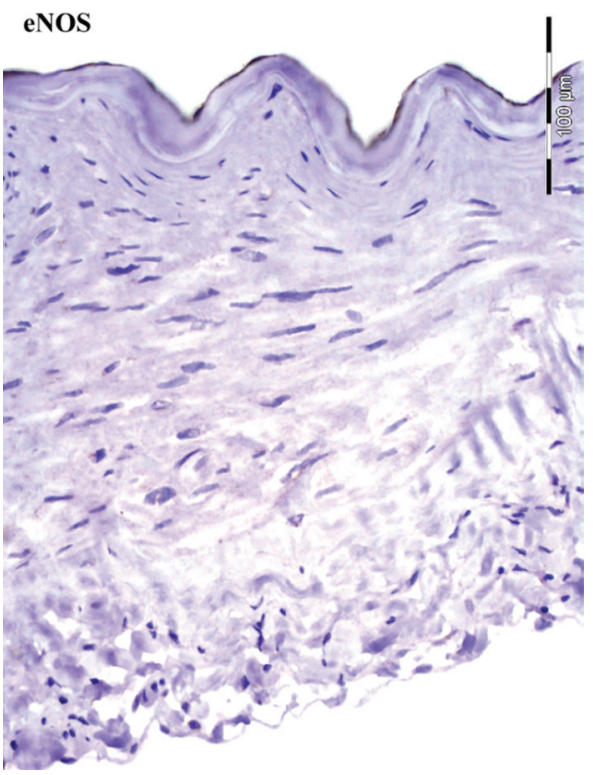

Figure 3. Positive endothelial nitric oxide synthase (eNOS) immunostaining.

CD34 proteins (Table 3), as well as endothelial nitric oxide synthase (eNOS) (Fig. 3). The subendothelial space, extending between the endothelial cells and the internal elastic lamina, is a very narrow layer without a visible content under the light microscope. Only in some cases the sub- 


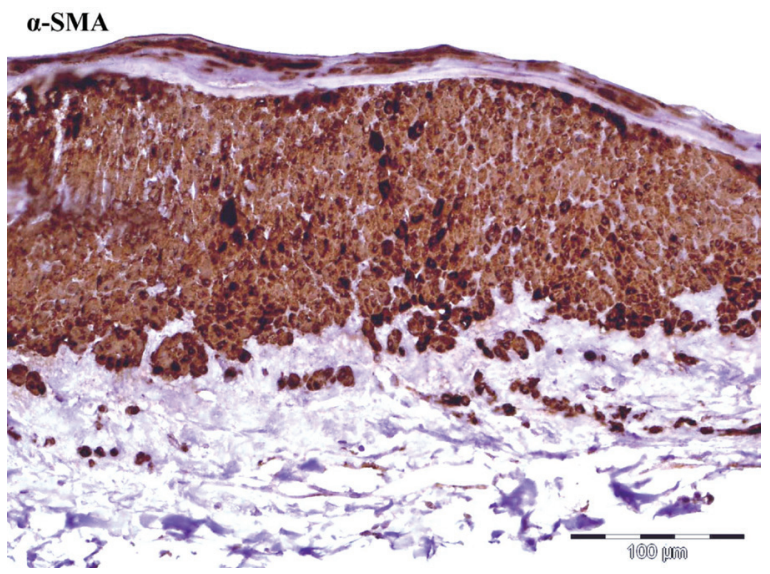

Figure 4. Positive smooth muscle $\alpha$-actin ( $\alpha$-SMA) immunostaining of the cells in the media coat, but also in the subendothelial space of a patient with the lenticulostriate arteries atherosclerosis.

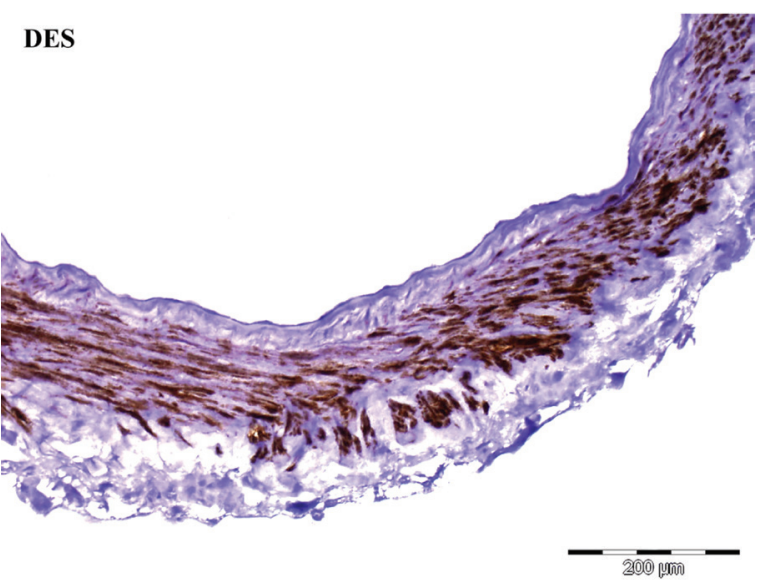

Figure 5. Positive desmine (DES) immunostaining in the tunica media, but negative in the tunica intima and adventitia.

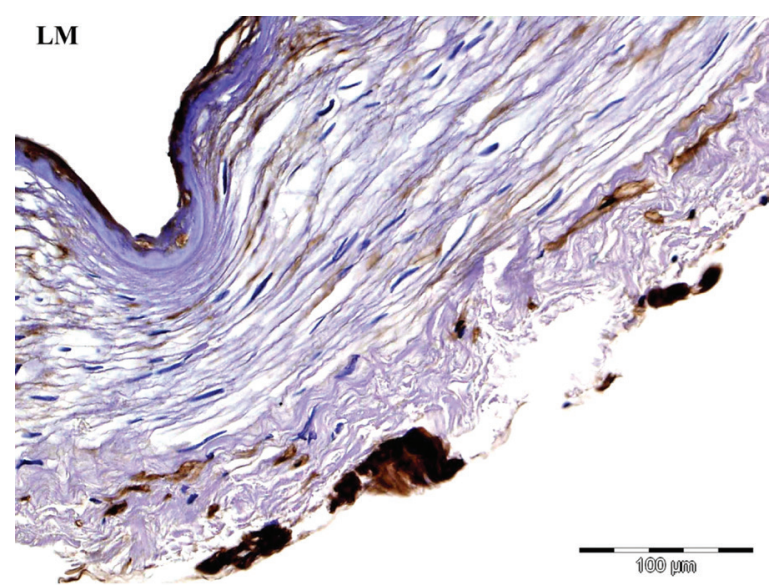

Figure 6. Positive laminin (LM) immunostaining in the intima, media, and adventitial coat of a transversely sectioned lenticulostriate arteries.

endothelial smooth muscle cells (SMC) were noticed. The immunostaining was positive for smooth muscle $\alpha$-actin

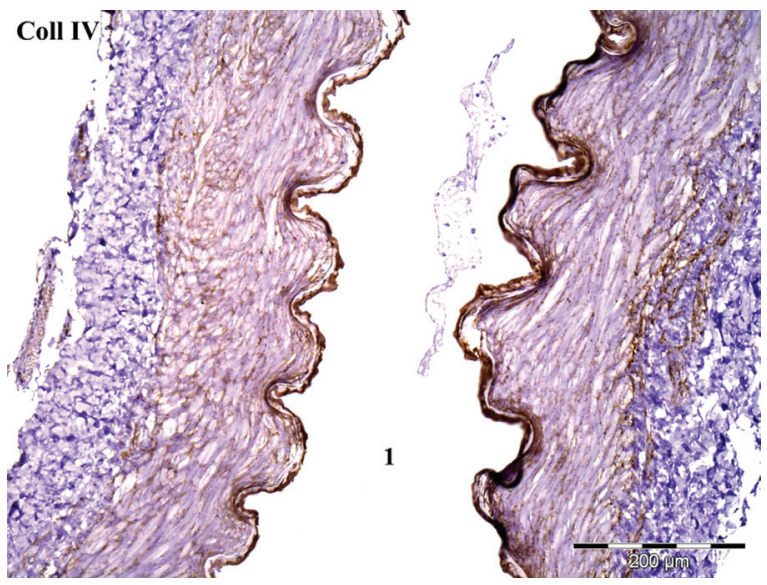

Figure 7. Positive collagen IV (Coll IV) immunostaining in the intima and media coat, and in the vascular nerves of a longitudinally sectioned lenticulostriate artery with labeled lumen (1).

( $\alpha$-SMA) occasionally, especially at the branching sites and in 3 patients with atherosclerosis, and for collagen IV (Coll IV) and laminin (LM), but negative for desmine (DES).

The internal elastic lamina (Fig. 2) presents as a homogenous structure between 4.3 and $14.6 \mu \mathrm{m}$ in thickness (Table 2). It is fragmented in the smaller side branches, and it disappears in the twigs with 2 or 3 layers of the SMC in their wall.

\section{Tunica media}

The media coat (Figs. 1, 2) averages $148.5 \mu \mathrm{m}$ in thickness (Table 2). It is mainly composed of the SMC, what was confirmed by positive immune reaction against the $\alpha$-SMA (Fig. 4) and DES (Fig. 5). The cells are arranged in layers that vary from 8 to 21 in number (mean 14.2). The extracellular matrix showed a positive immune reaction against LM (Fig. 6) and Coll IV (Fig. 7). The border between the media and adventitia was usually sharp, sometimes wave-like in appearance. The external elastic lamina was not present.

\section{Tunica adventitia}

The adventitial coat is only $109.3 \mu \mathrm{m}$ on average in diameter (Table 2). It is mainly composed of the fibroblasts, collagen fibers and nerve bundles (Figs. 1, $2,7)$. The fibroblasts with elongated nuclei and cellular processes have a typical appearance. There was a positive immune reaction against Coll IV (Fig. 7) and $S 100$ protein. The latter labeled the glial Schwann cells around the vascular nerve fibers. The basal lamina of these cells also showed a positive immunostaining for LM (Fig. 6). The axons themselves presented a strongly positive reaction against synaptophysin (SY) and neurofilament (NF) protein (Fig. 8, Table 3). 


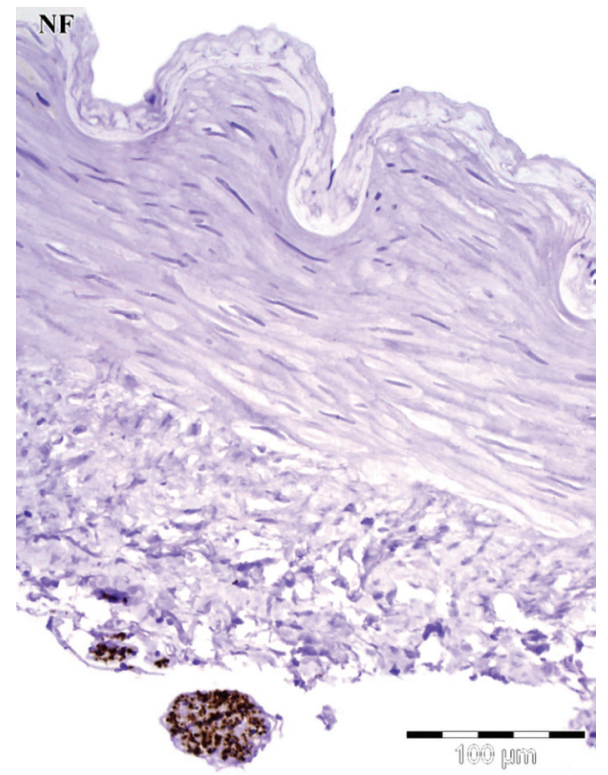

Figure 8. Positive neurofilament (NF) protein immunostaining of the vascular nerves. Note a periadventitial nerve bundle.

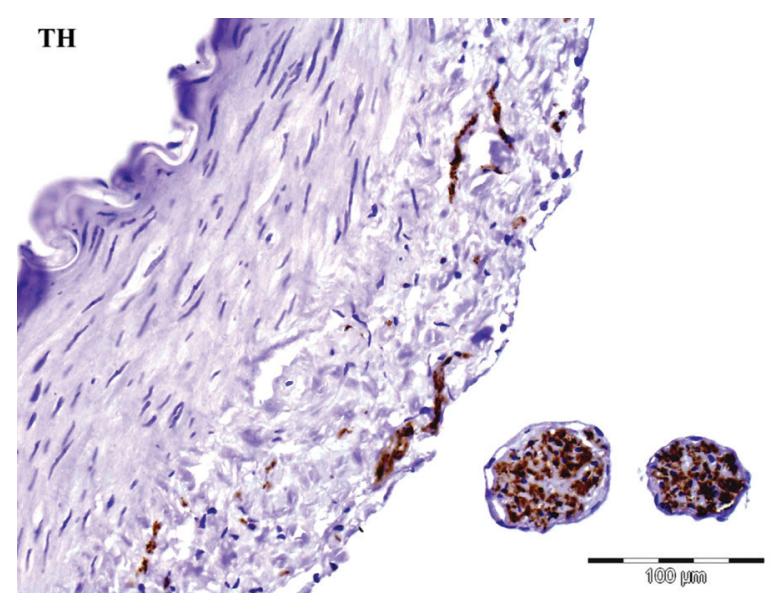

Figure 9. Positive tyrosine hydroxilase (TH) immunostaining of the vascular nerves.

Thanks to the immunostaining, we noticed first that some periarterial nerve bundles enter the adventitial coat, and coursed than through its most superficial part (Fig. 6). The bundles ramified into smaller groups of fibers which terminated very close to the outer layer of the SMC in the tunica media. The immune reaction was strong against tyrosine hydroxylase (TH) (Fig. 9), moderate or weak against acetylcholinesterase (AChE), and negative against serotonin or 5-hydroxitriptamine (5-HT) and c-KIT (Table 3). The latter result, along with a negative staining using toluidine blue, confirmed the absence of the perivascular and adventitial mast cells.

\section{DISCUSSION}

The LSAs are the small-sized vessels whose wall averages only $0.36 \mathrm{~mm}$ in diameter, their media coat $148.5 \mu \mathrm{m}$, and the adventitial coat 109.3 $\mu \mathrm{m}$ (Table 2). The other authors did not mention neither the thickness of the LSAs wall nor the diameter of their 3 coats. The small size of the LSAs and their thin wall may have several clinical implications.

Thus, the radiologists and neurosurgeons sometimes register a compression of the thin-walled LSAs by an aneurysm of the parent vessel, which is accompanied by the capsular or ganglionic ischaemia [21, 24]. The LSAs can also be damaged or become less patent in the course of neurovascular operations, for instance, when dissecting the perforating vessels from the wall of an aneurysm, placing a clip on the aneurysm neck, or applying a temporary MCA occlusion, as well as by direct iatrogenic injury to the LSAs [7].

The small orifices of the LSAs can be easily occluded by a dissecting aneurysm or an atheromatous plaque of the MCA, or artery-to-artery embolism $[4,19]$. The orifice occlusion can also follow an MCA stent deployment [12].

As regards the subarachnoid side branches of the LSAs, there is a progressive decrease of their size. Some of them are small vessels with only one layer of the SMC within the tunica media. This is, to our knowledge, the first evidence that the arterioles are also present in the subarachnoid space and not only in the brain parenchyma. This means that they also can be affected by the small vessel disease, particularly by lipohyalinosis and fibrinoid necrosis, with a consecutive focal brain ischaemia or hemorrhage, respectively $[1,6]$.

\section{Tunica intima}

The endothelial cells of the cerebral and other arteries can synthesise many substances, including CD31 and CD34 membrane proteins, NO, coagulation factors, endothelines and prostacyclin [25, 30]. Some of them belong to coagulation cascade or anticoagulant system, respectively, as well as to vasoactive agents and some other active substances.

The subendothelial space is a narrow zone that measures only $0.26-0.33 \mu \mathrm{m}$ in diameter in the cerebral arteries of the experimental animals. The space extends from the abluminal surface of the endothelial cells, i.e. their basement membrane, to the internal elastic lamina. The basement membrane mainly contains LM, fibronectin and Coll IV [2]. 
The cellular components in this zone are usually absent. If present, however, they most often comprise the subintimal SMC, which show a positive immune reaction against $\alpha$-SMA. The cells proliferation may appear in the perforating vessels of patients with systemic hypertension, atherosclerosis and some other vascular diseases $[1,15]$. The observed negative reaction against DES [15] was probably due to the fact that these muscle cells belong to the secretory and not to the contractile type.

The adjacent internal elastic lamina is a relatively thick structure in the LSAs wall. The lamina is thinner or fragmented in the LSAs side branches, and absent in the smallest twigs.

\section{Tunica media}

The SMC, which are the main components of the media coat, are elongated and interconnected by the gap junctions. The basal lamina of these cells also contains fibronectin and LM, which are present in the extracellular matrix as well, along with Coll IV and some other extracellular substances. The cells contain, among others, myofilaments, dense bodies and developed endoplasmic reticulum, and hence they show a positive immune reaction against the contractile protein $\alpha$-SMA and the intermediate fibers protein DES which is associated with dense bodies [2]. Obviously, the SMC contain a complete contractile system which regulates the size of the vessel lumen, i.e. vasoconstriction or vasodilation, and thus it controls the local blood flow.

The SMC are arranged in layers which vary between 8 and 21 in number, what was not reported thus far. Anyway, these cells have the central role in normal haemodynamics, but also in certain cerebrovascular disorders, especially in pathological vasoconstriction and spasm.

Cerebrovascular spasm, that is, a specific prolonged vasoconstriction, most often (in $30-40 \%$ ) is associated with the aneurysmal subarachnoid hemorrhage (SAH), and with head trauma (in $25-40 \%$ ) $[8,16,17,31]$. Spasm, which commonly appears 4 to 14 days following aneurysmal SAH, affects the circle of Willis and the main cerebral arteries, but also the perforating branches occasionally.

The cerebrovascular spasm manifests microscopically as an increase of the wall thickness and, as a consequence, a decrease of the luminal diameter $[8,17]$. Namely, the vasoactive substances from the clot, especially oxyhemoglobin, reactive oxygen species, serotonin and thromboxane-2, can induce a prolonged contraction of the SMC in the media coat. At the same time, some other substances from blood could activate the endothelial cells to release their vasoconstrictor agents, especially endothelin-1, or to disturb the endothelium-derived relaxing factors, such as NO and prostacyclin, which in turn increase and maintain contraction of the SMC [17]. All these processes may result in delayed cerebral ischaemia with consecutive neurological deficits $[8,16,17]$.

\section{Tunica adventitia}

The adventitial coat of the LSA averaged $109.3 \mu \mathrm{m}$ in diameter in our study. It mainly contains collagen and elastic fibers, fibroblasts, and nerve structures. Unlike some other cerebral arteries, the mast cells are not present in the LSAs. The extracellular matrix shows positive immune reactions against Coll IV and LM, especially in the basement membrane of the Schwann cells.

Bundles of the nerve fibers extend first around the LSAs, but they soon penetrate the adventitial coat and terminate within it, as observed in our study following the immune reaction against $\mathrm{S} 100$ protein, which is a calcium-binding protein expressed in neurons and glia, including the Schwann cells [3, 20]. A positive immune reaction was also registered against $S Y$, a protein in the presynaptic vesicles, and against NF protein, which forms the intermediate cytoskeletal filaments in the axons [2]. The axon terminals are often located close to the media coat, where they may form functional junctions with the SMC $[5,27]$.

Our examination showed a positive immune reaction against the enzyme $\mathrm{TH}$, related to catecholamines, i.e. norepinephrine (NE) and dopamine (DA), as well as AChE. Other authors revealed the existence of those and some other neurotransmitters in the LSAs wall, including $\mathrm{NO}$ and $5-\mathrm{HT}[3,9,11]$, as well as certain neuropeptides in the perforating arteries, particularly neuropeptide Y (NPY), calcitonin gene-related peptide (CGRP), gamma-aminobutyric acid (GABA), substance $P$ $(\mathrm{SP})$, vasoactive intestinal polypeptide (VIP), and brain natriuretic peptide (BNP) $[3,5,9,10,17,23,26]$. The neurotransmitters and neuropeptides, released from the adventitial nerve fibers, bind to the corresponding membrane receptors of the SMC to exert their action, i.e. vasoconstriction or vasodilation.

\section{CONCLUSIONS}

Data observed in our study are useful in exploration of the mechanism of some occlusive LSAs diseases, the cerebrovascular spasm, and the consecutive capsular or ganglionic ischaemia. They could also help the neurosurgeons to perform more safely the operations in the LSAs region. 


\section{ACKNOWLEDGEMENTS}

This work was supported by grant No. 175061 from the Ministry of Science, Serbia.

\section{REFERENCES}

1. Andrade MR, Pittela JEH (2009) Immunohistochemical identification of plasma protein deposits in the wall of lenticulostriate arteries in patients with long-standing hypertension, with and without lipohyalinosis. Arq Neuropshiquiatr, 67: 82-89.

2. Chan K-K, Lowe J (2002) Techniques in neuropathology. In: Theory and practice of histological techniques. $5^{\text {th }} \mathrm{Ed}$. Churchill Livingstone, London, pp. 271-320.

3. Chermousov MA, Carey DJ (2000) Schwann cell extracellular matrix molecules and their receptors. Histol Histopathol, 15: 593-601.

4. Choi HY, Yang YH, Cho HJ, Kim YS, Nam HS, Heo JH (2010) Systemic atherosclerosis in patients with perforating artery territorial infarction. Eur J Neurol, 17: 788-793.

5. Edvinsson L, Ekman R, Jansen I, Ottosson A, Uddman R (1987) Peptide-containing nerve fibers in human cerebral arteries: immunocytochemistry, radioimmunoassay, and in vitro pharmacology. An Neurol, 21: 431-437.

6. Fisher CM (1982) Lacunar strokes and infarcts: a review. Neurology, 32: 871-876.

7. Guo L, Gelb AW (2011) The use of motor evoked potential monitoring during cerebral aneurysm surgery to predict pure motor deficits due to subcortical ischemia. Clin Neurophysiol, 122: 648-655.

8. Humphrey JD, Baek S, Niklason LE (2007) Biochemomechanics of cerebral vasospasm and its resolution: I. A new hypothesis and theoretical framework. An Biomed Engin, 35: 1485-1497.

9. Jansen-Olesen I, Gulbenkian S, Engel U, Cunha e Sá M, Edvinsson L (2004) Peptidergic and non-peptidergic innervation and vasomotor responses of human lenticulostriate and posterior cerebral arteries. Peptides, 25: 2105-2114.

10. Kawamura K, Sakata N, Takebayashi S (1991) Neuropeptide $\mathrm{Y}$ - and vasoactive intestinal polypeptide-containing nerve fibers in the human cerebral arteries: characteristics of distribution. Angiology, 42: 35-43.

11. Kotsyuba AE, Kotsyuba EP, Chertok VM (2010) Nitroxidergic nerve fibers of intracerebral vessels. Neurosci Behav Physiol, 40: 451-455.

12. Levy El, Chaturvedi S (2006) Perforator stroke following intracranial stenting. A sacrifice for the greater good? Neurology, 66: 1803-1804.

13. Marinković S, Gibo H, Milisavljević M (1996) The surgical anatomy of the relationships between the perforating and the leptomeningeal arteries. Neurosurgery, 39: 72-83.

14. Masawa N, Yoshida Y, Yamada T, Joshita T, Sato S, Mihara B (1994) Morphometry of structural preservation of tunica media in aged and hypertensive human intracerebral arteries. Stroke, 25: 122-127.

15. Masuda J, Ogata J, Yutani C (1993) Smooth muscle cell proliferation and localization of macrophages and T cells in the occlusive intracranial major arteries in moyamoya disease. Stroke, 24: 1960-1967.

16. Neuschmelting V, Marbacher S, Fathi AR, Jakob SM, Fandino J (2009) Elevated level of endothelin-1 in cere- brospinal fluid and lack of nitric oxide arterial plasma associated with cerebral vasospasm after subarachnoid hemorrhage in rabbits. Acta Neurochir (Wien), 151: 795-801.

17. Oertel M, Boscardin WJ, Obrist WB, Glenn TC, McArthur DL, Gravori T, Lee JH, Martin NA (2005) Posttraumatic vasospasm: the epidemiology, severity, and time course of an underestimated phenomenon: a prospective study performed in 299 patients. J Neurosurg, 103: 812-824.

18. Ohkuma H, Suzuki S (1999) Histological dissociation between intra- and extraparenchymal portion of perforating small arteries after experimental subarachnoid hemorrhage in dogs. Acta Neuropathol, 98: 374-382.

19. Ohkuma H, Suzuki S, Shimamura N, Nakano T (2003) Dissecting aneurysms of the middle cerebral artery: neuroradiological and clinical features. Neuroradiology, 45: 143-148.

20. Ohtani R, Tomimoto H, Wakita H, Kitaguchi H, Nakaji K, Takahashi R (2007) Expression of S 100 protein and protective effect of arundic acid on the rat brain in chronic cerebral hypoperfusion. Brain Res, 1135: 195-200.

21. Oka H, Oki H, Ohbayashi M, Fukami T (1986) A case of unruptured $A 1$ aneurysm causing ischemic compression to the medial proximal striate artery. No Shinkei Geka, 14: 1613-1617.

22. Rosner SS, Rhoton AL, Ono M, Barry M (1984) Microsurgucal anatomy of the anterior perforating arteries. J Neurosurg, 61: 468-485.

23. Saper CB, Kibbe MR, Hurley KM, Spencer S, Holmes HR, Leahy KM, Needleman P (1990) Brain natriuretic peptide-like immunoreactive innervation of the cardiovascular and cerebrovascular systems in the rat. Circul Res, 67: 1345-1354.

24. Sasaki T, Kodama N, Matsumoto M, Suzuki K, Konno $Y$, Sakuma J, Endo Y, Oinuma M (2007) Blood flow disturbance in perforating arteries attributable to aneurysm surgery. J Neurosurg, 107: 60-67.

25. Scekanecz Z, Koch AE (2002) Biology of endothelial cells. Vasculitis, Oxford University Press, New York.

26. Shimizu T, Koto A, Suzuki N, Morita Y, Takao M, Otomo S, Fukuchi $Y$ (1999) Occurrence and distribution of substance $P$ receptors in the cerebral blood vessels of the rat. Brain Res, 830: 372-378.

27. Suzuki N, Hardebo JE (1993) The cerebrovascular parasympathetic innervation, Cerebrovasc Brain Metab Rev, 5: 33-48.

28. Tagami M, Nara Y, Kubota A, Sunaga T, Maezawa H, Fujino H, Yamori Y (1987) Ultrastructural characteristics of occluded perforating arteries in stroke-prone spontaneously hypertensive rats. Stroke, 18: 733-740.

29. Tatu L, Moulin T, Bogousslavsky J, Duvernoy H (1998) Arterial territories of the human brain: cerebral hemispheres. Neurology, 50: 1699-1708.

30. Vatter $H$, Mursch K, Zimmermann M, Zilliken $P$, Kolenda $H$, Seifert V, Schilling L (2002) Endothelin-converting enzyme activity in human cerebral circulation. Neurosurgery, 51: 445-451.

31. Weidauer S, Lanfermann H, Raabe A, Zanella F, Seifert V, Beck J (2007) Impairment of cerebral perfusion and infarct patterns attributable to vasospasm after aneurysmal subarachnoid hemorrhage. A prospective MRI and DSA study. Stroke, 38: 1831-1836. 